\title{
Status Crystallization and Mobility Lock: The Poverty Production Process*
}

\author{
John Tropman, Emily Nicklett \\ School of Social Work, The University of Michigan, Ann Arbor, MI, USA \\ Email: tropman@umich.edu
}

How to cite this paper: Tropman, J., \& Nicklett, E. (2019). Status Crystallization and Mobility Lock: The Poverty Production Process. Advances in Applied Sociology, 9, 478-490.

https://doi.org/10.4236/aasoci.2019.910035

Received: August 26, 2019

Accepted: October 26, 2019

Published: October 29, 2019

Copyright $\odot 2019$ by author(s) and Scientific Research Publishing Inc. This work is licensed under the Creative Commons Attribution International License (CC BY 4.0).

http://creativecommons.org/licenses/by/4.0/

\begin{abstract}
While America is nominally the "land of opportunity", it is more so for some than others. Those in the lowest and next-to-lowest class quintiles are especially disadvantaged. Numerous efforts to be helpful seem to have not worked well probably due to a lack of opportunities and misaligned interventions. For the most part, residents in these classes seem to be stuck in their positions. This paper hypothesizes that "status crystallization" in the bottom quintiles (low on income, low on wealth, low educational attainment, and manual/episodic low status work/job) creates a "quadruple helix" of intertwined deficits that can "lock" individuals and families in a poverty position. This "mobility lock" contributes to the persistence of poverty status in spite of numerous social programs and health services. These five variables-income, wealth, educational attainment, occupation type and health-are all forms of personal capital that contribute to the opportunities for social mobility in the United States. High values on these variables act as "compound interest", accelerating mobility; low values function as the opposite-sort of the "payday loan": effectively trapping those individuals in lower and ever decreasing status. However, as discussed in this article (and by others), personal capital alone does not sufficiently predict opportunities for social mobility in the United States. Social capital-or the networks of relationships that contribute to living and working in a given society-provide and enhance opportunities for social and economic mobility. As pointed out by Raj Chetty and others, the conditional probability of upward mobility is also enhanced by geographic location, or "opportunity areas". Higher opportunity places shared qualities associated with upward mobility: good schools, greater levels of social cohesion, many two-parent families, low levels of income inequality and little residential segregation either by class or race (Gareth Cook, 2019, The Atlantic). Low values on these factors may tend to co-exist in some areas and become "impediment areas" as opposed to mobility enhancement ones.
\end{abstract}

${ }^{\star}$ We want to express our deep appreciation to Dan Madaj for his wonderful help in preparing this paper. 


\section{Keywords}

Poverty, Social Stratification, Social Mobility. Mobility Lock, Stratification

Crystallization

\section{Introduction}

"That dream of a land in which life should be better and richer and fuller for everyone, with opportunity for each according to ability or achievement" (The Epic of America, James Truslow Adams, 1931: p. 404).

The idea of The American Dream entails an implicit promise: that the virtues of hard work and determination will be rewarded by providing a vehicle for social mobility from the lower to the upper, classes of American society, or at least a higher one regardless of one's familial status or standing. Immigrants have been coming to America for years, many dying to get here. When the concept of the American Dream was coined in the early 1930s, it embodied developments brought about by transformational social change. This transformation had several elements - the immigration beginning in 1850 or so of European Catholics and Jews, the Civil War, industrial capitalism in post-Civil War America, and the opportunities for upward mobility offered as a result. Despite the economic setbacks of the Great Depression, the comeback and growth of the post-WWII US economy-and the emergence of the American middle class-imprinted this "dream" on US national identity. While it is true that America and many Americans have accumulated vast material wealth (as measured by a recent International Monetary Fund Report, IMF 2019), the presence and persistence of poverty in the US challenging the perception that-with enough sweat-anybody ${ }^{1}$ can get ahead in America.

Despite the great wealth and economic prosperity enjoyed by some in the United States, the poor, in many ways, seem to remain "stuck". Efforts by social workers, beginning with the first Charity Organization Society in Buffalo New York around $1877^{2}$ (they originated in England) seemed helpful but insufficient. Various programs under the Social Security Act (originally Old Age Assistance, Aid to the Blind and Aid to Dependent Children) were helpful but generated some resentment and were changed several times. ${ }^{3}$ These programs were palliative rather than aimed at assisting in upward mobility.

\footnotetext{
${ }^{1}$ As discussed in Jim Cullen's (2003) The American Dream: A Short History of an Idea that Shaped a Nation, this ideal was also restricted in terms of race: "Upward mobility remained possible, but the terms had a decisively racial cast. For much of American history, then upward mobility was understood, even defined, by a visible alternative of immobility" (p. 61).

${ }^{2} \mathrm{https}$ ://socialwelfare.library.vcu.edu/eras/civil-war-reconstruction/charity-organization-societies-1877-1893/

${ }^{3}$ Tropman (1977) noted in an article in Policy Sciences that Aid to Dependent Children became Aid to Families with Dependent Children and then Temporary Assistance to Needy Families. Aid to the Blind and Old Age Assistance was moved into the Social Security Administration and became Supplemental Security Income.
} 


\section{2. "Wars on Poverty" from the 1950s to the Current Day: A Brief Review}

By the 1950s, interest in other approaches to a "safety net" developed, including the Wars on Poverty, restructuring of the welfare system, and additional means-tested strategies for poverty alleviation.

The "Grey Areas" Program of the Ford Foundation was developed to take a more community-focused and philanthropically-driven approach to poverty relief. Because previous social work efforts were largely regarded as failures, social workers were largely excluded from the program (Jerome Cohen, 1964, "Social Work and the Culture of Poverty") and new organizational forms were developed. Robert Kennedy, Chair of the President's Committee on Juvenile Delinquency when he was Attorney General, became interested in developing a program, centered on the Bedford Stuyvesant housing project in New York City, and poised to go nationwide. ${ }^{4}$ It began as Mobilization for Youth, and morphed into the War on Poverty, which in turn morphed into other initiatives, generally called CDCs or Community Development Corporations. The CDCs have provided many civic improvements in American cities, emphasizing sustainable development, locally-owned business advocacy, and community organizing, but none have "cracked" the poverty problem or provided significant escape routes from the lowest class. With the Personal Responsibility and Work Opportunity Reconciliation Act (PRWORA) of 1996, President Clinton ended "welfare as we know it" by replacing the Aid to Families with Dependent Children (AFDC) with the Temporary Assistance for Needy Families (TANF) program and imposing strict limitations on the receipt of means-tested benefits, with the idea that sufficient incentive and motivation can end the cycle of poverty. It hasn't.

Today we have Food Assistance SNAP-Supplemental Assistance to Needy Families, and Women and Infants Care (WIC) ${ }^{5}$, the Earned Income Tax Credit ${ }^{6}$ and Head Start. ${ }^{7}$ There are other strategies and programs to "alleviate" poverty as well-which have not been successful. Poverty problems remain and appear to be increasing. ${ }^{8}$ Most of the programs focus on one variable-providing income, education and training, healthcare access, and decreasing the racial wealth gap as suggested in a recent report. ${ }^{9}$ The problem seems to be that in a multicausal problem single factor interventions are not that effective, although they

\footnotetext{
${ }^{4}$ For an excellent discussion of these early efforts and the people involved see Scott Koehler's (1966) excellent write-up "Bedford-Stuyvesant and the Rise of the Community Development Corporation" https://cspcs.sanford.duke.edu/sites/default/files/descriptive/bedford-stuyvesant.pdf. ${ }^{5}$ https://www.usa.gov/food-help

${ }^{6}$ https://www.irs.gov/credits-deductions/individuals/earned-income-tax-credit

'https://www.acf.hhs.gov/ohs

${ }^{8}$ As characterized in a recent US Government General Accountability Office Report (https://www.gao.gov/assets/710/700836.pdf) and as covered by the New York Times

(https://www.nytimes.com/2019/09/10/us/politics/gao-income-gap-rich-poor.html), the expanding gap between rich and poor is truly "getting under the skin" of Americans, resulting in substantial differences in health outcomes and longevity for the rich and the poor.

9"The economic impact of closing the racial wealth gap", available at:

https://www.mckinsey.com/industries/public-sector/our-insights/the-economic-impact-of-closing-t he-racial-wealth-gap.
} 
do provide some needed help.

Current proposals and strategies continue this tradition of focusing on singular determinants of poverty and mobility lock. The Affordable Care Act (ACA) attempts to unravel the ties between poverty, health status, and access to health care. Other strategies target racial injustices in wealth, income, and mobility, such as reparations and ongoing debates around affirmative action. Proposals for free post-secondary education and student loan forgiveness attempt to share the gains from the GI Bill to the rest of the US population. Due to the continued perception of "deserving" poor (e.g. US veterans) versus "undeserving" poor (immigrants, non-whites) in the United States, these proposed strategies are a divisive point in current US politics and their success largely depends on who has the power to define deservedness and to make those distinctions.

\section{Popular Causal Theories}

Intertwined with these structural and organizational efforts were some theories/hypotheses about the etiology of poverty. One was community competence (or, for poor communities, perceived community incompetence!).

Community competence, or the ability of a community to problem solve and achieve community goals, suggests that, if community competence could be increased, community problems could be solved (or at least managed) and impediments removed. Community competence has been espoused by a number of the helping professions, including Nursing, Public Health, Community Organization in Social Work, and serves a diagnostic function as well. There is no standard practice for providing activities that would increase community competence, however, and it could be (and was) used as a community level version of "blaming the victim" rather than addressing social and structural factors, which contribute to poverty and inequality. ${ }^{10}$

Another set of theories was the "culture of poverty" discussion. Introduced in a seminal article by Oscar Lewis in 1966, the concept suggests that the poor have a culture that gives them meaning and coping strategies that create, sustain and exacerbate poverty. It was negatively received however, as "blaming the victim" and research into it and related ideas, perceived as "politically incorrect" or downright racist, ground to a halt. As Patricia Cohen (2010) observes in the New York Times.

The reticence was a legacy of the ugly battles that erupted after Daniel Patrick Moynihan, then an assistant labor secretary in the Johnson administration, introduced the idea of a "culture of poverty" to the public in a startling 1965 report. Although Moynihan didn't coin the phrase (that distinction belongs to the anthropologist Oscar Lewis), his description of the urban black family as caught in an inescapable "tangle of pathology" of unmarried mothers and welfare dependency was seen as attributing self-perpetuating moral deficiencies to black ${ }^{10}$ An interesting contemporary discussion of inequality: https:/getpocket.com/explore/item/a-nobel-prize-winning-economist-thinks-we-re-asking-all-thewrong-questions-about-inequality 
people, as if blaming them for their own misfortune.

Her article, "Culture of Poverty" Makes a Comeback touched on the early history and then goes on to discuss its "resurrection":

The old debate has shaped the new. Last month Princeton and the Brookings Institution released a collection of papers on unmarried parents, a subject, it noted, that became off-limits after the Moynihan report. At the recent annual meeting of the American Sociological Association, attendees discussed the resurgence of scholarship on culture. And in Washington last spring, social scientists participated in a Congressional briefing on culture and poverty linked to a special issue of The Annals, the journal of the American Academy of Political and Social Science. ${ }^{11}$

Individuals and communities experiencing poverty are targeted and blamed for such circumstances. Using a biopsychosocial approach, espoused in particular by the Social Work profession, these circumstances are also structural in nature and largely affected by the policies that determine how resources are allocated in society. Currently, many policies (recent tax reforms, "sin taxes", etc.) extract and redistribute funds from poor to rich, exacerbating the poverty problem and blaming the poor in the process.

\section{Contemporary Thinking}

Some of the most exciting recent thinking (and research thinking) on poverty stagnation has been done by Raj Chetty at Harvard University. ${ }^{12}$ He points out that the American rate of relative mobility (moving from the lowest class to the highest class) is under $8 \%$ :

The chances of making it, Horatio Alger-style, from a childhood in poverty to an adulthood in affluence (i.e. moving from bottom to top income quintile) are lower in the US than in other nations. The American Dream is in better shape in Canada, as Figure 1 below suggests. ${ }^{13}$

As shown in Figure 1 below, in the United States there appears to be a high correlation between initial status and final status. It is worth noting at this point that not only is the US at the bottom of the ladder among comparable states on mobility.

A similar bottom position wealth equality. Edward Wolff in his new book $A$ Century of Wealth in America, reports 11 findings, which he summaries in the preface; two are especially relevant here. First, that wealth inequality has increased in the last four decades. Second, that mobility is relatively more "closed" in the US compared to other wealthy countries:

\footnotetext{
${ }^{11}$ This site sources many discussions of "Culture and Poverty" including the Annals book https://www.google.com/search?q=Culture+and+Poverty+Tha++Annals+\&ie=utf-8\&oe=utf-8\&clie nt=firefox-b-1.

${ }^{12}$ Raj Chetty in 14 charts, Brookings blog:

https://www.brookings.edu/blog/social-mobility-memos/2018/01/11/raj-chetty-in-14-charts-big-fin dings-on-opportunity-and-mobility-we-should-know/ See also "The Economist Who Would fix the American Dream", The Atlantic:

https://www.theatlantic.com/magazine/archive/2019/08/raj-chettys-american-dream/592804/.

${ }^{13}$ The table is Figure 1 in the Brookings mobility memo above.
} 


\section{Relative mobility is almost twice as high in Canada}

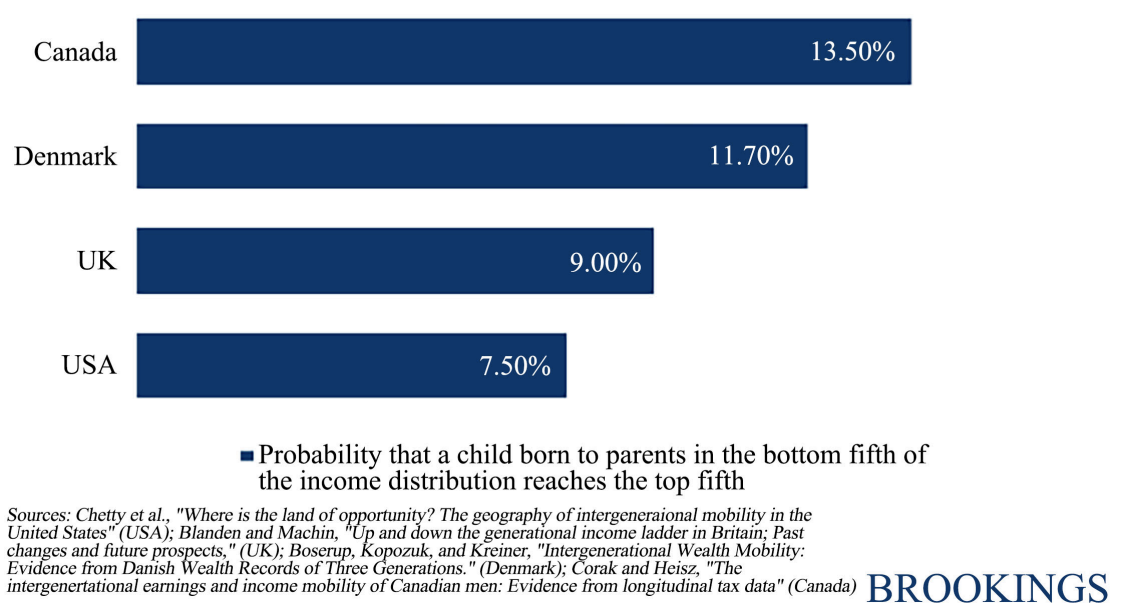

Figure 1. Relative mobility in selected industrialized countries (used with permission).

The amazing turnabout of the United States ... By any conceivable index-household income, equivalent income, poverty, wealth the United States today is the most unequal country (or nearly so) among the advanced industrial nations of the world (p. xiv).

So we are at the top of the ladder, so to speak, for inequality and near the bottom for mobility. ${ }^{14}$

Chetty tends to focus on economic mobility (earnings, wealth) while sociologists include income (not wealth so much) and add in education, occupational status, residential location, and sometimes power. Chetty does include residential location variable in his paper (with others) entitled "Where is the Land of Opportunity".

We use administrative records on the incomes of more than 40 million children and their parents to describe three features of intergenerational mobility in the United States. First, we characterize the joint distribution of parent and child income at the national level. The conditional expectation of child income given parent income is linear in percentile ranks. On average, a 10 percentile increase in parent income is associated with a 3.4 percentile increase in a child's income. Second, intergenerational mobility varies substantially across areas within the US For example, the probability that a child reaches the top quintile of the national income distribution starting from a family in the bottom quintile is $4.4 \%$ in Charlotte but $12.9 \%$ in San Jose. Third, we explore the factors correlated with upward mobility. High mobility areas have 1) less residential segregation, 2) less income inequality, 3) better primary schools, 4) greater social capital, and 5) greater family stability. While our descriptive analysis does not identify the causal mechanisms that determine upward mobility, the publicly available statis-

${ }^{14}$ According to an international report by Julia Isaacs from The Brookings Institution, the United States is among the most "closed" systems in terms of social mobility among highly industrialized societies, along with Italy and Great Britain:

https://www.brookings.edu/wp-content/uploads/2016/07/02_economic_mobility_sawhill_ch3.pdf. 
tics on intergenerational mobility developed here can facilitate future research on such mechanisms.

Given the low rate of mobility one might want to invert the causal question-what prevents mobility? Some good candidates would be the opposite of the points Chetty and his colleagues made (Chetty et al., 2014).

\section{Social Class Levels}

In order to explore this question, a model of the American stratification system would be helpful, starting with five variables-the classic 3-Income, Educational level Income, and Occupational Level (see Robert Hodge, 1981 on measures of occupational status). To these we would add Wealth and Health, Wealth has not been a typical variable in stratification studies, but given the importance of Assets, it seemed important to include it. Health, to our knowledge has never been included in a stratification score, but given its costs, financial and otherwise, it seemed important to include. These, plus the "Chetty 5" Give us ten to consider.

We propose that the stratification system is shaped like a diamond with an open top. Divided into quintiles the classes would be 5 . The Upper Class; 4 . The Upper Middle Class; 3 . The Middle Class; 2. The Working Class; 1 . The Lowest Class (Figures 2-4).

\section{Social Class Indicators}

The members of a class would be assigned based on where one's Vector Value falls on the class measure (Personal Capital; Only Here).

\begin{tabular}{|l|l|}
\hline \multicolumn{2}{|l|}{ SOCIAL AND PERSONAL STATUS VARIABLES } \\
\hline $\begin{array}{l}\text { Chetty - } \\
\text { Social Capital }\end{array}$ & $\begin{array}{l}\text { Tropman \& Nicklett - } \\
\text { Personal Capital }\end{array}$ \\
\hline Residential Segregation & Income \\
\hline Income Inequality & Wealth \\
\hline Schools & Education \\
\hline Social Capital & Job \\
\hline Family Stability & Health \\
\hline
\end{tabular}

Figure 2. Proposed social capital and personal capita; status variables.

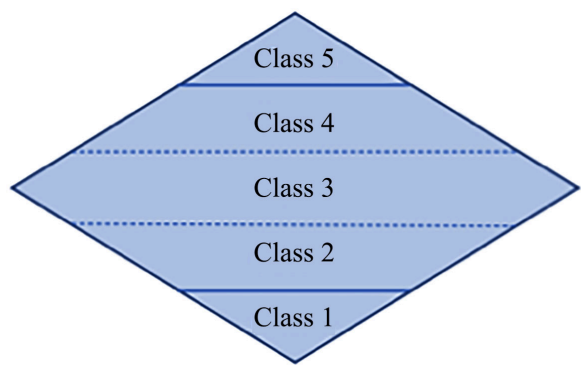

Figure 3. Theoretical stratification system model. 


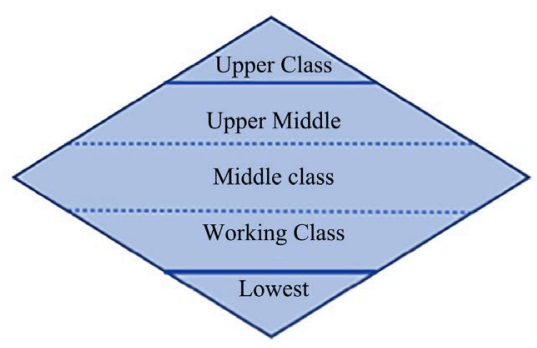

Figure 4. Stratification system shaped like a diamond.

Income:

5. High Income (top 5th)

4. Upper Middle (4th 5 th)

3. Middle Income (3rd 5th) $4^{\text {th }}$ Forth

2. Lower income (2nd 5 th)

1. Lowest Income (1st Fifth)

Education:

5. Graduate/Professional Degree

4. College Graduate

3. Some College/Community College

2. High School Graduate

1. Less than High School

Occupation:

A job score might be one of the prestige scores available but also using the following:

5. Higher end Professional work with a Professional Degree required 4 Professional Work

3. White Collar Work

2. Manual Work/trades

1. No job, pickup job

Wealth

Wealth would be measured by asset level:

5. Very Substantial Assets

4. Substantial Assets

3. Median Assets

2. Low assets

1. No Assets

Health

Health would be measured using a subjective measure of self-reported health using the question, this single item captures different dimensions of health.

"In general, would you say that your health is?

5. Excellent,

4. Very good,

3. Good,

4. Fair, or

5. Poor?" 


\section{Personal and Social Capital Variables}

Individuals would have 10 scores, one for each of the measures. Were this research to actually be done, Chetty would need to give values for his measures. A perfect score, so to speak, would be 50 (all in the upper class) and a stressful score would be 10 (all in the lowest class). (If the research was done on either social or personal capital variables alone, the top score would be 25). Individual scores would be assigned to classes in the following way. Let's assume we have data on that each individual over Individual at 35 years of age. Each as a score on these 10 vectors, which can be obtained through Census records or de-identified population-based survey data. If the stratification system is divided into quintiles, then we could look for status consistency and then create as score for each "participant". A general structure would probably be that, if an individual is in the lowest quintile on one variable, they have a high conditional probability of being low on a second variable. The greater the number of variables for which individuals are situated in the lowest quintile, the higher the conditional probability that they will rank in the bottom quintile for the remaining vectors. High status consistency-being low on all five, would be highest in the lowest quintile, lower in the fourth quintile, lowest in the third (or middle) quintile, and somewhat higher in the second and first quintile (Figure 5).

We hypothesize that the resulting distribution would look something like a diamond, with the greatest number of individuals in the middle class (less stratification crystallization, and fewer as one moved from the middle to the top and the middle to the bottom). The point here is that the absence of positional resources creates "mobility lock" in the lower two quintiles. Anyone can act as a drag on mobility possibility but being low on several is a mobility anchor, which sustains over generations. Being at the bottom of the heap, so to speak, gives one nothing to "trade". Being at the top of the heap allows resource conversion-some wealth can replace income, income can replace some wealth, either may overcome low educational attainment, and so on.

\section{Discussion}

Perhaps the persistence of poverty (or the inheritance of poverty, so to speak) can be partially explained by the concept of mobility lock. Two dynamics may be operating here.

\begin{tabular}{|lll|}
\hline CLASS LEVELS & SCORE & DESCRIPTION \\
\hline Upper Class & $42-50$ & $\begin{array}{l}\text { Protected Class/ } \\
\text { Some Lock }\end{array}$ \\
\hline Upper Middle Class & $34-41.9$ & $\begin{array}{l}\text { Somewhat } \\
\text { Open }\end{array}$ \\
\hline Middle Class & $26-33$ & $\begin{array}{l}\text { Most } \\
\text { Open }\end{array}$ \\
\hline Working Class & $19-26$ & $\begin{array}{l}\text { Somewhat } \\
\text { Closed }\end{array}$ \\
\hline Lowest Class & $10-18.9$ & $\begin{array}{l}\text { Restricted Class/ } \\
\text { Mobility Lock }\end{array}$ \\
\hline
\end{tabular}

Figure 5. Class levels and scores. 
The first is that being low on the status variables means you start out with a disadvantage. You have less of everything that might help you rise. Second, you have less of a buffer and less to invest in opportunities that could lead to upward mobility. Those in the lowest class most likely have to focus on "staying alive" rather than "working to thrive", especially if they also live areas with fewer economic opportunities.

This point is also stressed in the book Pressure Cooker. Why Home Cooking Won't Solve Our Problems and What We Can Do About It. The authors, Sarah Bowen, Joslyn Breton, and Sinikka Elliot (2019), point out that women do the majority of food preparation (and cleanup!) while they are also working moms leaving little time is left for anything else. (In the food area they often get little help from their husbands.) They also tend to have the bulk of child management tasks. This is what Arlie Hochschild (2003) called The Second Shift (in her book, The Second Shift). If you are a single mom, you are also coping with lower income and even more responsibilities. Even if you are in an intact family the husband's "at will" employment may mean episodic work multiple jobs and low pay. There is no easy-bake solution to the problem of status crystallization and mobility lock in the United States.

\subsection{How Did We Get Here? How and Why Do We Stay Here?}

We got in the low mobility/high inequality spot because poverty alleviation strategies are univariate and uncoordinated, rather than multidimensional and coordinated approaches. We are a typical hospital model rather than a Mayo Clinic model.

The helping efforts we described in the beginning of this paper were all well-intended but tended to "rebound" from the failures of their predecessors. And each failure tended to reinforce culturally convenient notions of "blaming the victim" and "shooting the messenger" rather than looking at the combined root causes and predisposing elements within the American sociocultural fabric.

\subsection{How Can We Help?}

In the subtitle to the "pressure cooker" book- "Why Home Cooking Won't Solve Our Problems and What We Can Do About It" - the authors find answers in the application of universal social policy of helping-such as child allowances - that are used in other countries successfully to provide everyone a basic floor of at least income as a social right. It is not as much of a "social safety net" as a "social floor" and springboard. But we are disinclined to follow these examples in this country.

To help those in need at the bottom of the social ladder, combined efforts at the development of personal capital and social capital are needed, but we in America do not seem to have the will or the interest in approaching social policy this way, Rather we seem to want to exploit the poor (and other targets like some elderly) through extracting rent, or getting them to work for free or cheap, we 
discussed in "Balancing the Budget through Social Exploitation: Why Hard Times Are Even Harder for Some" (Tropman \& Nicklett, 2012). ${ }^{15}$ America shies away from "social policies of helping". We prefer the "mountain man" approach to the "wagon train" approach, the "each tub on its own bottom" to "a rising tide lifts all boats". Perhaps that is one of the reasons America is lowest on the mobility chart that Chetty shows us.

Part of the reason for our "each tub on its own bottom" approach to social policy is our disdain for the poor, as Tropman, 1998, discussed in his book, Does America Hate the Poor? We spend a lot of time "partializing the poor" into "the lowest class" and the "next to the lowest class", the latter often called the "deserving poor" or "people who need a little help from the government". The lowest class people are often discussed in derogatory terms such as "welfare cheats", "lazy bums", and "on the dole".

Arthur Schlesinger Jr. discusses some of these attitudes, especially those of the business elite, in his book The Age of Roosevelt. Businessmen regarded unemployment as a form of malingering: "Anything was better than the dole" As an example of this, "poorhate", (or poorism) a plan proposed by John B. Nichlos, involved serving garbage to the poor, a proposal we call "The Pigs Breakfast".

Thus John B. Nichlos of the Oklahoma Gas Utilities Company wrote to his friend Patrick J. Hurley, the Secretary of War, about an idea he was trying out in Chickasha, Oklahoma. By the Nichlos plan, restaurants were asked to dump food left on plates into five gallon containers; the unemployed could quality for these scraps by chopping wood donated by farmers. "We expect a little trouble now and then from those who are not worthy of the support of the citizens". Nichlos wrote philosophically, but we must contend "with such cases in order to take care of those who are worthy". Hurley was so impressed by the plan of feeding garbage to the homeless that he personally urged it on Colonel Woods [an advisor to President Franklin Roosevelt] (Schlesinger, 1957, The Crisis of the Old Order).

But work is needed at the upper end as well. Thomas Piketty \& Arthur Goldhammer (2017) talk about a "wealth tax" (Capital in the 21 st Century), something that the wealthy do not support, for the most part, though they cannot spend all that they have. The idea is not exactly new. During WWII there was an "excess profits tax", the difference here being that it is usually used in times of war and is on corporations? However, the idea that well to do citizens complain about paying for social programs should be replaced by positive steps instead of endless carping about welfare cheats, the undeserving poor, and the insecurity of social security.

\section{Conclusion}

American Society will not be successful at increasing mobility and lessening inequality unless we "unlock" the mobility gateways. This unlocking means coor-

${ }^{15}$ By way of illustration, see Campbell Robertson (2019), In Echo of Labor Wars, Unpaid Miners Block a Coal Train. The New York Times, August $20^{\text {th }}, 2019$ p. A10. 
dinated programs addressing the simultaneity of disadvantage of social and personal capital. The call for coordination, made by Bradley Buell and Associates (1952) sixty-seven years ago in the book, Community Planning for Human Services, remains unheeded. Rather, common tropes about the disadvantaged-that they are criminals, that they are lazy, that they are gaming/ripping off the system-continually bubble up in public discourse and public policy. Regrettably, America seems to be moving in the opposite direction, with mass incarceration and neighborhood policing strategies, through the rejection, criminalization, and demonization of immigrants, and sending SNAP program participants from pillar to post.

The work presented here provided a more comprehensive conceptual framework, but conceptual frameworks do not always persuade, as in the case of climate change. Work needs to be done at the top end as well. Social inequality is funded by social exploitation, underpaying vulnerable groups and overcompensating the privileged. It would go a long way to start with an excess wealth tax and a more sensible inheritance tax.

\section{Conflicts of Interest}

The authors declare no conflicts of interest regarding the publication of this paper.

\section{References}

Adams, J. T. (1931). The Epic of America. New York: Simon Publishers.

Bowen, S., Brenton, J., \& Elliott, S. (2019). Pressure Cooker. New York: Oxford University Press.

Buell, B. et al. (1952). Community Planning for Human Services. New York: Columbia University Press. https://doi.org/10.7312/buel90702

Chetty, R., Hendren, N., Kline, P., \& Saez, E. (2014). Where Is the Land of Opportunity? The Geography of Intergenerational Mobility in the United States. The Quarterly Journal of Economics, 129, 1553-1623. https://www.nber.org/papers/w19843 https://doi.org/10.1093/qje/qju022

Cohen, J. (1964). Social Work and the Culture of Poverty. Social Work, 9, 3-11. https://doi.org/10.1093/sw/9.1.3

Cohen, P. (2010). https://www.nytimes.com/2010/10/18/us/18poverty.html

Cook, G. (2019). The Economist Who Would Fix the American Dream. The Atlantic. https://www.theatlantic.com/magazine/archive/2019/08/raj-chettys-american-dream/5 $\underline{92804}$

Cullen, J. (2003). The American Dream: A Short History of an Idea That Shaped a Nation (p. 61). Oxford: Oxford University Press.

Hochschild, A. (2003). The Second Shift. New York: Penguin.

Hodge, R. (1981). The Measurement of Occupational Status. Social Science Research, 10, 396-415. https://doi.org/10.1016/0049-089X(81)90012-0

International Monetary Fund (2019). Report for Selected Country Groups and Subjects (PPP Valuation of Country GDP).

https://www.imf.org/external/datamapper/PPPSH@WEO/OEMDC/ADVEC/WEOWO 
$\underline{\text { RLD }}$

Koehler, S. (1966). Bedford-Stuyvesant and the Rise of the Community Development Corporation. Ford Foundation. https://cspcs.sanford.duke.edu/sites/default/files/descriptive/bedford-stuyvesant.pdf

Lewis, O. (1966). The Culture of Poverty. Scientific American, 215, 19-25. https://doi.org/10.1038/scientificamerican1066-19

Piketty, T., \& Goldhammer, A. (2017). Capital in the 21st Century. London: Belknap Press. https://doi.org/10.4324/9780429499821-9

Robertson, C. (2019). In Echo of Labor Wars, Unpaid Miners Block a Coal Train. The New York Times, A10.

Schlesinger Jr., A. (1957). The Age of Roosevelt. Rolling Meadows, IL: Riverside Press.

Tropman, J. (1977). American Welfare Strategies: Three Programs under the Social Security Act. Policy Sciences, 8, 33-48. https://doi.org/10.1007/BF01727600

Tropman, J. (1998). Do Americans Hate the Poor? The Other American Dilemma. Westport: Prager.

Tropman, J., \& Nicklett, E. (2012). Balancing the Budget through Social Exploitation: Why Hard Times Are Harder for Some. Advances in Applied Sociology, 2, 111-119. https://doi.org/10.4236/aasoci.2012.22015 